\title{
A solução para o problema da saúde é mista e solidária
}

\author{
ARLINDO DE ALMEIDA
}

$\mathrm{O}$

SISTEMA SUPLETIVO de planos e seguros privados de assistência à saúde, reconhecidamente de elevado alcance social, atende hoje cerca de 41 milhões de pessoas, uma população quatro vezes maior do que a de Portugal, equivalente a mais de dois terços da força de trabalho do país. É estruturado em um universo empresarial heterogêneo, não apenas pela diversidade com que opera, mas também pela variedade do porte de cerca de 1.500 empresas operadoras de planos de saúde.

O setor é constituído pela medicina de grupo, que surgiu no início da década de 60 . Trabalha com estrutura própria, além de serviços credenciados, e é responsável pela cobertura de 18,3 milhões de beneficiários, $82,5 \%$ deles constituídos de trabalhadores e seus familiares, cujos planos, chamados de coletivos ou empresariais, são custeados no todo ou em parte por 48,5 mil empresas contratantes.

Com características idênticas às da medicina de grupo, surgiram em 1967, na forma de cooperativas, as Unimeds, cuja participação no mercado é da ordem de 10,7 milhões de beneficiários. Mais recentemente o segurosaúde, vendido e administrado por seguradoras que atuam no mercado com outros produtos, sem estrutura médico-assistencial própria, na forma de reembolso de despesas com consultas, exames, internação, no limite da apólice contratada, que tem quatro milhões de segurados.

Além desses segmentos, existe ainda o sistema de autogestão, organizado por empresas públicas e privadas, com administração própria ou contratada, que atua exclusivamente no atendimento dos quadros funcionais da empresa e de seus dependentes, e é responsável pela assistência a oito milhões de pessoas.

\section{A nova forma de financiar o atendimento}

As primeiras apólices de seguro individual de acidentes e de saúde surgiram nos Estados Unidos em meados do século passado, evoluindo para o seguro coletivo após os anos 20 deste século. A seguir desenvolve- 
ram-se organizações empresariais de prestadores de serviços médicos que constituíram as medicinas de grupo, nas quais os médicos negociavam seus honorários em nível inferior ao praticado, compensados pela ampliação da clientela. E foi no clima da Grande Depressão em 1929, que surgiu em Dallas, Texas (EUA), uma nova norma de financiar a atividade hospitalar, o plano de seguro-saúde.

Idealizado e posto em prática por um hospital, destinava-se a um grupo de professores e seus familiares, mediante um pré-pagamento mensal em troca da garantia e do direito de internação de até 21 dias/ano, uso do centro cirúrgico e de alguns serviços auxiliares. Criava corpo a experiência norte-americana da época dos assentamentos de suas ferrovias em regiões inóspitas e desassistidas, quando as empreiteiras reuniam e contratavam médicos e equipamentos, improvisando hospitais de campanha para a prestação de atendimento àqueles trabalhadores.

No Brasil, o embrião do sistema supletivo de saúde com atendimento médico-hospitalar foi formado em São Paulo, em 1956, quando uma empresa de porte expressivo desativou seu serviço de saúde contratando, a seguir, os serviços de um grupo de médicos, entre eles os que desempregara, para dar assistência aos seus funcionários mediante um pré-pagamento fixo.

Mas foi no início dos anos 60 que surgiu e se desenvolveu o sistema privado, a partir do ABC, região metropolitana de São Paulo, na esteira do crescimento industrial acelerado pela implantação da indústria automobilística. Médicos se organizaram em grupos, criando uma estrutura de atendimento com custos fixos e previsíveis para preencher o vazio deixado pelo Estado, que já demonstrava sua incapacidade em acompanhar o novo momento, caracterizada pela queda na qualidade do atendimento médicohospitalar oferecido pelo setor público, longas filas de espera e superlotação dos hospitais.

De outro lado, os altos custos da medicina, crescentes até mesmo pela explosão do desenvolvimento tecnológico, reduziram o atendimento particular que, então, ainda era comum.

Dessa forma surgiu a medicina de grupo, um sistema de elevado padrão técnico-profissional, com serviços e hospitais próprios e uma estrutura de atendimento que inclui médicos contratados e conveniados, serviços auxiliares de diagnóstico e tratamento especializado, além de programas de medicina preventiva. Repetia-se aqui a experiência daqueles pioneiros, organizando-se o sistema que se firmou e se desdobrou rapidamente em segmentos, no galope da crescente deterioração do serviço público. 
Os custos médicos, que até há algumas décadas podiam ser assumidos por uma família com renda razoável como parte eventual de suas despesas domésticas, tornaram-se inviáveis, conduzindo as pessoas para os planos de saúde ou para os serviços públicos. Com a deterioração do serviço público e a melhoria do poder aquisitivo da população, mesmo pessoas das classes D e E passaram a ser consumidores potenciais dos planos de saúde.

\section{Parceria para que se complementem}

A área de assistência à saúde no país vivencia uma crise que não é apenas financeira, mas também de ordem política e organizacional. Indicadores referentes à mortalidade infantil, à infecção hospitalar, à falta de água tratada e de esgotos em impressionantes contingentes populacionais, inclusive nas grandes cidades, colocam o Brasil na lista dos países mais pobres do mundo, agravando o problema de saúde da população e fazendo com que doenças de séculos passados, como a cólera e outras, já erradicadas ou controladas em grande parte do mundo, estejam presentes em nosso meio.

O que se espera do Estado é a cobertura essencial na área de saúde, utilizando melhor os seus recursos, concentrando-os na promoção do saneamento básico, no controle de qualidade dos alimentos e dos medicamentos, dos portos e dos vetores causadores de epidemias, além de que promova correta fiscalização, tanto na área pública quanto na privada. À livre iniciativa compete principalmente a prestação da assistência médica, complementando a ação do Estado, mas sem a sua interferência.

A realidade demonstra que a iniciativa privada, sustentada por investimentos de empresários que pagam planos de saúde para seus empregados (e que deveriam ter algum estímulo por parte do governo) e pelas pessoas que pagam pelos próprios planos individuais ou familiares, representa o sustentáculo da prática médica de qualidade no Brasil.

Os planos e seguros privados de assistência à saúde são parte da solução, não do problema. Eles pretendem ser parceiros do Estado, complementando-o onde este, sozinho, não esteja sendo capaz. Mas em uma parceria na qual haja respeito mútuo, para que se complementem; parceiros cientes de que os negócios têm de ser justos, não podendo resultar em vantagens ou desvantagens para uma só parte. Ambos precisam estar satisfeitos.

A solução do problema saúde no Brasil é, pois, mista e solidária: deve ser o resultado da atuação conjunta dos setores públicos e privados, unindo esforços, mas com papéis específicos, cabendo aos primeiros especial- 
mente as ações básicas como o saneamento. Nessa aliança destaca-se, ainda, a importância da existência de vasos comunicantes entre a livre iniciativa e o setor público, em que aquela colabore com o Estado no controle de epidemias e endemias e em planos de vacinação, e este oferecendo na área da assistência médica serviços de referência, principalmente através de hospitais universitários e outros centros.

\section{Regulamentação não realiza o sonho impossível}

A criação e a expansão dos planos privados estão intimamente ligados à história do sistema brasileiro de saúde pública. É preciso levar em conta essa história para se discutir as atribuições do Estado na área, assim como as do setor privado.

À falta de diretrizes oficiais - antes mesmo da instituição do Código de Defesa do Consumidor em 1990 - o sistema de medicina de grupo criou um órgão, o Conamge (Conselho Nacional de Auto-regulamentação das Empresas de Medicina de Grupo), para cuidar e cobrar ética das empresas filiadas e prestar orientação e defesa aos usuários de planos de saúde de empresas associadas à Abramge. O Conamge é uma ponte entre a medicina de grupo e o usuário. Ele acolhe e procura solucionar reclamações, inclusive com a possibilidade de punição para a empresa faltosa.

A Lei $n^{\circ} 9.656 / 98$, que só agora regulamentou os planos, em vigor desde janeiro, e suas medidas provisórias, portarias do Ministério da Saúde e normas da Susep não realizaram o sonho impossível de quantos desejavam obrigar o setor privado a substituir o Estado em seus deveres constitucionais. Mas puseram em risco aquele, ao tentar criar um paraíso de benefícios sem atentar aos novos custos impostos às operadoras, acentuados pelas novas regras, até porque as obrigam a expandir a cobertura para todas as doenças, inclusive as mentais, Aids, assistência aos drogados, transplantes e procedimentos de alta complexidade; oferecer internações sem limite, inclusive em UTI e para o neonato; garantir manutenção de cobertura para inadimplência até 60 dias, cobrir doenças preexistentes, manter as condições contratuais de plano empresa para aposentados e demitidos. Proíbe também o aumento por faixa etária, após a idade de 60 anos, para aqueles que contribuem há dez anos.

Acrescentam-se a esses fatores as exigências de constituição de capital ou garantia de solvência, manutenção e equilíbrio econômico-financeiro, com auditoria externa, adequação e controles atuariais para dimensionar custos, provisões e garantias, normas exigidas para as seguradoras, que têm 
características diferentes, porque funcionam como instituições financeiras reembolsando despesas. Não se levou em conta as características de cada um, o universo em que atua e sua finalidade básica. Enquanto os planos têm de ofertar serviços assistenciais, as seguradoras reembolsam em dinheiro e não em serviços as despesas com assistência à saúde de seus segurados. É de se considerar ainda que nem todos os planos existentes se propõem a cobrir transplantes, hemodiálises e tratamentos mais sofisticados. Até por falta de condições técnicas.

\section{O Estado quer se livrar de suas atribuições}

Para se ter idéia da complexidade do universo de planos de saúde no país, vale examinar o estudo realizado pela Comissão Mista Especial Médica e Econômica da Abramge, encaminhado em maio de 1998 para o Ministério da Saúde e para a Susep, com a distribuição geográfica e o porte das empresas associadas à Abramge.

São poucas as empresas concentradas nas grandes capitais, como São Paulo e Rio de Janeiro. As médias já aparecem em outros estados e em grandes cidades do interior. O grupo de empresas de porte intermediário, com população coberta entre 10 e 50 mil usuários, está localizado em cidades de médio porte e até em algumas capitais, abrangendo maior número de estados. Já as empresas menores, com menos de 10 mil usuários, representando $62,25 \%$ do universo dos planos de saúde daquelas associadas à Abramge, encontram-se espalhadas pelo interior e pelas periferias das grandes cidades, cujos serviços são oferecidos por pequenos hospitais e santas casas, sem recursos sofisticados. Por isso mesmo, comercializam planos baratos, com as limitações decorrentes, mas suficientes para a maioria das necessidades de seus contratantes. São planos que cobrem uma apendicite, uma fratura de braço, um parto e que, com as novas regras, devem desaparecer. $\mathrm{E}$, pior, é que as empresas de grande porte não chegam a essas pequenas localidades; se chegarem, a maioria de sua população não terá recursos para contratar seus planos.

Essa distribuição serve, principalmente, para que se classifiquem os níveis de cobertura dos diferentes contratos, pois as empresas de maior porte oferecem, na maioria dos casos, planos bastante amplos em termos de cobertura. Por atuarem nos grandes centros, onde dispõem de amplos recursos materiais e humanos, com toda a inovação tecnológica, além da grande massa que assistem lhes é permitida a diluição dos riscos inerentes a tais garantias, além de contarem com o poder aquisitivo da população. 
Quanto menor o tamanho da empresa e seu avanço pelo interior do país, o nível de cobertura se reduz, pois os fatores que permitem aquela amplitude das grandes operadoras faltam às menores. Nessas regiões e faixas a limitação de recursos físicos e humanos, a maior dificuldade de atualização tecnológica regional e o menor número de beneficiários, associados ao baixo poder aquisitivo da população, implicam a impossibilidade de assumir grandes riscos.

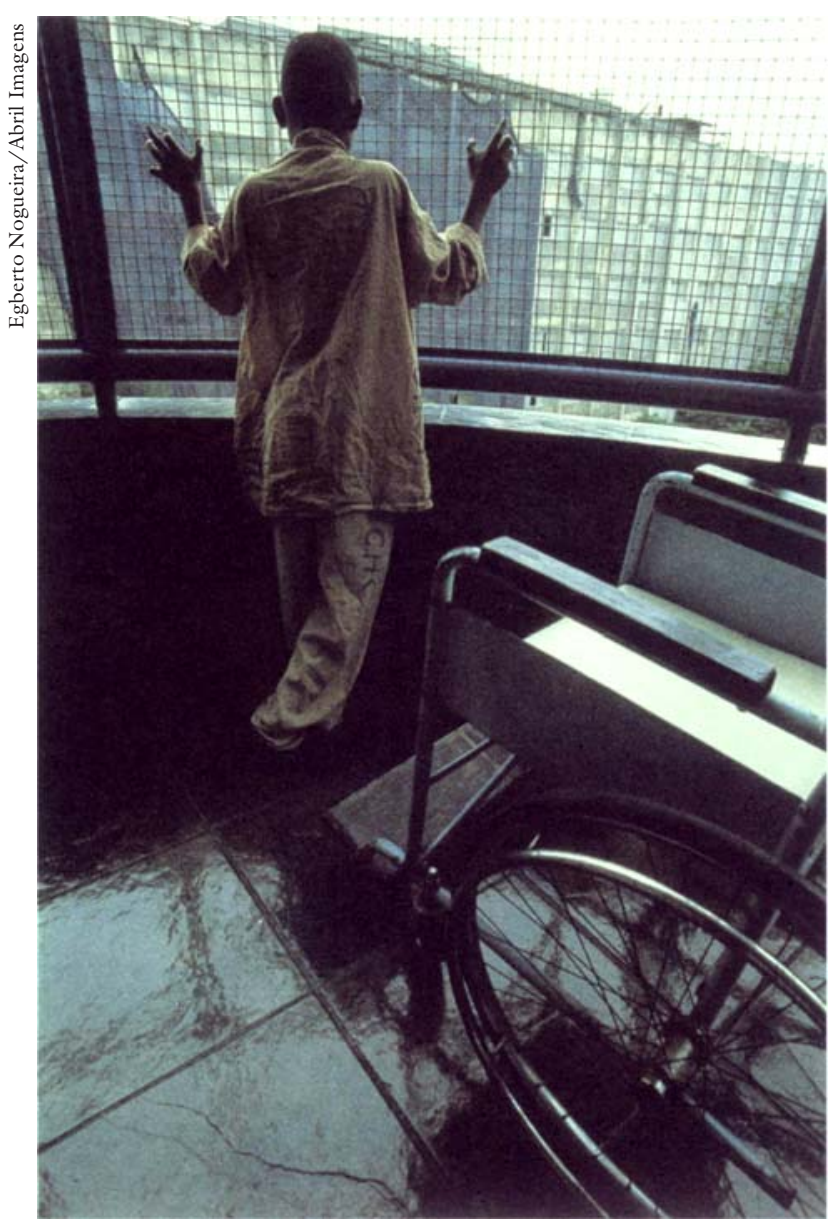

Paciente do Hospital das Clínicas, SP

À parte, dispositivos da lei que questionamos por inconstitucionais, com a retroatividade para intervir nos contratos celebrados antes da vigência da lei, atingindo $o$ ato jurídico perfeito e o direito adquirido, e que não pretendemos discutir aqui, o que chama atenção nessa legislação é a intenção clara do goverrno de querer se eximir de suas obrigações constitucionais, transferindo-as ao cidadão usuário - porque este terá de arcar com o ônus da manutenção de um plano - e às operadoras uma carga impossível de obrigações. Tal aspecto se enquadra na teoria de redução do tamanho do Estado, com transferências de suas incumbências para terceiros. Mas é ao Estado que compete essa obrigação e só ele pode cobrir os gastos de saúde dos mais pobres, com o dinheiro que arrecada dos impostos.

\section{Grau de satisfação, na opinião do consumidor}

Pesquisa realizada pela Toledo \& Associados, para a Rádio Bandeirantes de São Paulo em setembro de 98, mostra o elevado grau de satisfação dos usuários com os planos de saúde: 79\% (23\% muito satisfeitos e 56\% satisfeitos), $14 \%$ indiferentes e $7 \%$ insatisfeitos. A consulta foi feita em 38 cidades paulistas, envolvendo duas mil pessoas de variada condição sócio- 
econômica, pela qual se constatou que 46\% das famílias ouvidas têm convênios médicos. As pessoas que se manifestaram justificam sua satisfação pelo excelente atendimento, rapidez na marcação de consulta, atenção e cordialidade com que normalmente são atendidas e tratadas.

Tal resultado, que contraria críticas de casos isolados freqüentemente reproduzidas com alarde pela imprensa, aproxima-se e confirma os graus de satisfação já aferidos em pesquisas anteriores, como as promovidas pelo Ibope em 1995, com 89\% de aprovação; e pela Fiesp/Ciesp, juntamente com o Sindicato dos Trabalhadores nas Indústrias Metalúrgicas, Mecânicas e de Material Elétrico de São Paulo em 1994: entre as empresas do setor (56,73\% com convênios de medicina de grupo para os seus empregados), $80 \%$ delas definiram o nível de satisfação com os convênios médicos como bom $(66,37 \%)$ e muito bom $(14,41 \%)$. As demais os qualificaram como regulares $(19,91 \%)$ e ruins $(0,30 \%)$.

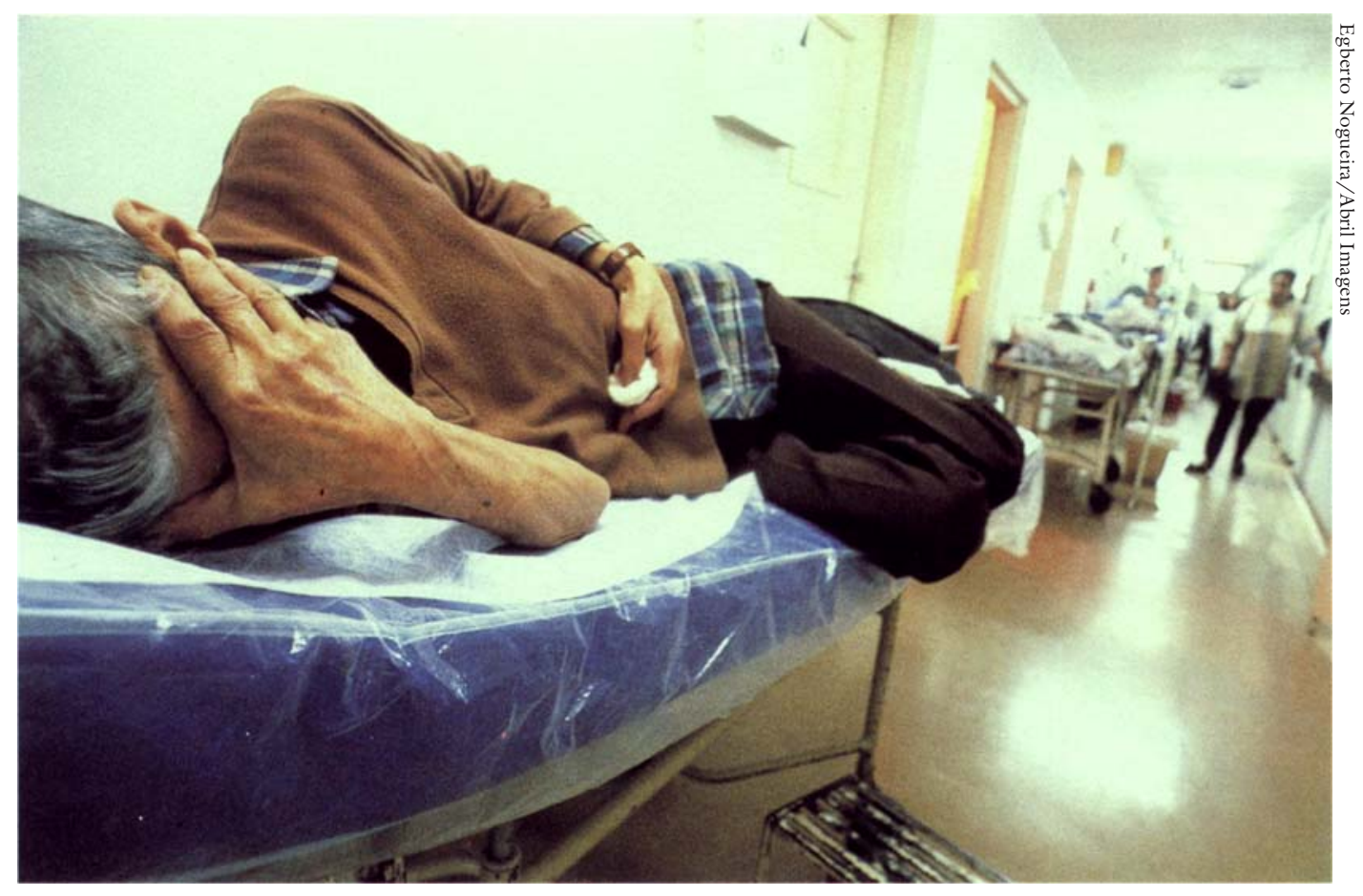

Paciente espera ser atendido deitado na maca no corredor do Pronto Socorro do Mandaqui, SP

\section{Mais de um milhão de procedimentos/dia}

Um paralelo entre os sistemas público e privado revela notável diferença. Enquanto a medicina de grupo gasta mensalmente US\$ 17,94 per 
capita/usuário, o setor público não vai além de US\$ 4,16. O sistema, no seu todo (medicina de grupo, cooperativa, autogestão e seguradora), movimentou em 1998 US\$ 16,03 bilhões.

Nos últimos seis anos a rede pública perdeu 5.929 leitos, reduzindo de 3,32 para 3,1 o número de vagas por mil habitantes, enquanto só a medicina de grupo ampliou em 6.400 os seus leitos próprios no período de 94 a 97 , sem contar os leitos credenciados, cerca de 300 mil.

O setor privado realiza mais de um milhão de procedimentos médicos em cada dia útil. Só isso dá a dimensão de sua importância. Sozinha, a medicina de grupo realizou, no ano de 98, 90,6 milhões de consultas médicas, 1,810 milhão de internações hospitalares, 380 mil partos, 55,5 milhões de exames laboratoriais, 9,1 milhões de exames radiológicos, 2,5 milhões de exames por ultra-som, 811 mil por eletroencefalograma, 2 milhões por eletrocardiograma, além de 12,9 milhões de outros exames e serviços auxiliares de diagnóstico e terapia, movimentando cerca de US\$ 3,940 bilhões.

Arlindo de Almeida, médico, é presidente da Abramge (Associação Brasileira de Medicina de Grupo). 